each cell. By this a considerable proportion of these acids is neutralized. In the treatment of the juice the solution of the problem seems to have rested rather in the simplification of the method to be used than in its further complication. In fact, it is really a return to first principles, as it were; for the method which was finally adopted, and which has given such excellent results, is the old method of liming the juice to a slightly alkaline re-action, and boiling and skimming in an open pan. No filtration is used whatever, the scums being simply returned to the cells, where they are again extracted, so that no loss of sugar is sustained. Treated in this way, the diffusion juice shows a higher coefficient of purity than juice obtained from the same cane by pressure, also an increased ratio of sucrose to glucose.

Single experimental runs have given a yield as high as one hundred and thirteen pounds of 'first sugar' to the ton of cleaned cane, with seventeen and a half pounds of 'second sugar,' or a total of one hundred and thirty pounds to the ton. This is at least twice as large a yield as has ever been obtained by pressure extraction, even under the most favorable conditions. The results on the season's work have not yet been ascertained.

The people of Kansas are highly pleased over the results of the work so far, and, with characteristic Western energy, are preparing to rush into the sugar-business immediately, and make Kansas, in the language of the local newspapers, 'rival Louisiana' as a sugarproducing State. A few words of caution to these would-be sugargrowers might not come amiss. No industry requires more careful management, or a greater amount of scientific knowledge and skill, to make it a success, than the production of sugar. In order to compete with other sugar-producing countries and plants, the most careful system of cultivation should be combined with the most skilful and economical methods of manufacture. The beet-sugar industry of Europe may well serve as a model in this respect, in that the proper cultivation of the beet-roots is regarded as of prime importance, and in the manufacture of the sugar every pound of waste or by-product is utilized, and every ton of fuel is made to yield its maximum equivalent of power. The most careful and thorough scientific supervision is exercised over the entire process of manufacture. At the present prices for sorghum-seed, which is in great demand for planting for forage purposes and for the sirup, a yield of any thing in the neighborhood of one hundred pounds of sugar to the ton of cane would afford a very wide margin on the cost of production, since the cane can be grown for one dollar and fifty cents per ton; but the success of the industry would necessarily involve the reduction of the prices for these important by-products to a much lower figure, and cut off a very considerable proportion of the present profits in the production. On the other hand, much is to be hoped from the apparently great adaptability of the plant to the soil and climate of a large area of this country, and from scientifically conducted experiments for the increase of its saccharine content. Judging from analogy, it is reasonable to expect that the latter can be greatly increased by the well-known methods of selection and cultivation. Sorghum-cane has been grown on the grounds of the Department of Agriculture at Washington, which contained as high as eighteen per cent of sucrose in the juice, or sixteen per cent of the cane. If a field of sorghum could be raised which would average fifteen per cent of sucrose without too great an expenditure for cultivation, the question of the profitable production of sugar from the plant would be solved at once.

This much, at least, can be said of the experiments that have been carried on by the Department of Agriculture: they have shown that good marketable sugar can be made from sorghumcane in sufficient quantities to pay at the present prices for the products and by-products of the manufacture. The question as to whether we are to have a national sugar-industry in the United States will probably work out its own solution before many years.

These experiments in the manufacture of sugar should have a particular interest for scientific men, for their success means not only a triumph of science, but also a complete vindication of the policy of giving governmental aid to scientific investigations. The development of the sorghum-sugar industry so far has been carried on entirely by the Department of Agriculture, with appropriations made by Congress for that purpose. Numerous objections have been raised against these appropriations, and both loud and deep have been the repinings as the years went on and no practical outcome was obtained. In case they are crowned with ultimate success, these objectors will be most fitly answered; for the money spent would be but as a molecule of water to the Mississippi River in comparison with the stream of wealth which would flow from the establishment of a national sugar-industry. Let us hope the lesson will have its effect upon the people in the adoption of a still more liberal policy in aiding scientific research in the future. The experiments in the application of the diffusion to Louisiana cane will be commenced some time in October. From the favorable results which were obtained last fall at Fort Scott in operating upon a few carloads of cane after the close of the sorghum season, it may reasonably be expected that the yield obtained will be very satisfactory, although the problem is somewhat more difficult than in the case of sorghum, as the results obtained by mill-extraction from the Southern cane are much superior to those obtained from sorghum.

Fort Scott, Kan., Oct. 23.

C. A. CRAmpton.

\section{The Purslane-Worm.}

IT may be of interest to note that the 'purslane-caterpillar,' described in a recent number of Science (x. No. 246), has made its appearance at this point ; at least, a new species of caterpillar, new to all observers, and feeding on purslane, has made itself very conspicuous for a few months past. In this vicinity the early summer was very dry, and the purslane, which is not yet so common a weed with us as farther east, was not very plentiful. But late in August, after a series of heavy showers, it sprang up, more suo, abundantly, and with it came this stranger in such numbers as to attract the notice of one quite unlearned in such matters. Both the plant and its boarder flourished along the line of a railroad leading south-east into Kansas, from which State it is in all probability an emigrant; but, if so, one would think that it must have advanced farther last season than your Kansas correspondent noted.

Hastings, Neb., Oct. 25.

Geo. M. WhICHER.

\section{Queries.}

i6. Pennsylvania Pot-Holes. - Can you tell me where I can find an account of the glacial pot-hole noticed in your 'Notes' in No. 246? I presume it may be in some volume of the Second Geological Survey of Pennsylvania, but I do not know which one. Perhaps some of your readers can say, if you cannot.

Oxford, O., Oct. 23. JOSEPH F. JAMES.

17. Does Bituminous Coal contain any Bitumen ?Many text-books and dictionaries define bituminous coal as containing bitumen, and mislead the student into the belief that its name is due to this fact. In Vol. VI., 'Encyclopædia Britannica,' ninth edition, Mr. H. Baurerman, F.G.S., Royal School of Mines, says on p. 46, under the subject coal, "The most important class of coals is that generally known as bituminous, from their property of softening, or undergoing an apparent fusion, when heated to a temperature far below that at which actual combustion takes place. This term is founded on a misapprehension of the nature of the occurrence, since, although the softening takes place at a low temperature, still it marks the point at which destructive distillation commences, and hydrocarbons both of solid and gaseous character are formed. That nothing analogous to bitumen exists in coals, is proved by the fact that the ordinary solvents for bituminous substances, such as bisulphide of carbon, and benzole, have no effect upon them, as would be the case if they contained bitumen soluble in these re-agents. The term is, however, a convenient one, and one whose use is almost a necessity from its having an almost universal currency among coal-miners." Impressed with the above statement, and recognizing its importance to teachers of science especially, I call attention to it, under the head of 'Queries,' that hereafter truth shall be taught, and not error. I sometimes entertain a suspicion that many errors continue to be accepted as facts, because writers simply copy from their predecessors, instead of actually testing or proving them to be facts.

Muncy, Penn., Oct. 28. 